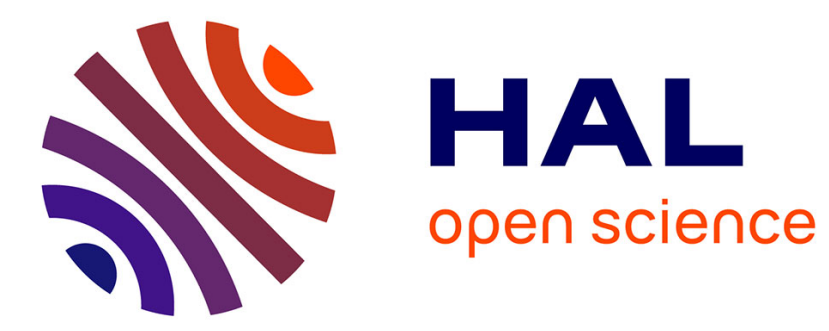

\title{
Temperament and parental child-rearing style: unique contributions to clinical anxiety disorders in childhood
}

\author{
Ingeborg E. Lindhout, Monica Th. Markus, Thea H. G. Hoogendijk, Frits
}

Boer

\section{- To cite this version:}

Ingeborg E. Lindhout, Monica Th. Markus, Thea H. G. Hoogendijk, Frits Boer. Temperament and parental child-rearing style: unique contributions to clinical anxiety disorders in childhood. European Child and Adolescent Psychiatry, 2009, 18 (7), pp.439-446. 10.1007/s00787-009-0753-9 . hal00478105

\section{HAL Id: hal-00478105 \\ https://hal.science/hal-00478105}

Submitted on 30 Apr 2010

HAL is a multi-disciplinary open access archive for the deposit and dissemination of scientific research documents, whether they are published or not. The documents may come from teaching and research institutions in France or abroad, or from public or private research centers.
L'archive ouverte pluridisciplinaire HAL, est destinée au dépôt et à la diffusion de documents scientifiques de niveau recherche, publiés ou non, émanant des établissements d'enseignement et de recherche français ou étrangers, des laboratoires publics ou privés. 
Ingeborg E. Lindhout

Monica Th. Markus

Thea H.G. Hoogendijk

Frits Boer

\section{Temperament and parental child-rearing style: unique contributions to clinical anxiety disorders in childhood}

Received: 5 June 2008

Accepted: 21 December 2008

Published online: 5 February 2009
I.E. Lindhout, $\mathrm{MD}, \mathrm{PhD}(\bowtie)$

Triversum, Centre for Child and

Adolescent Psychiatry

PO Box 225

1800 AE, Alkmaar, The Netherlands

Tel.: +31-72/5140376

Fax: $+31-72 / 5140300$

E-Mail: ilindhout@triversum.nl

M.Th. Markus, PhD - T.H.G. Hoogendijk Academic Centre for Child and Adolescent Psychiatry Curium

Endegeesterstraatweg 27

2342 AK Oegstgeest, The Netherlands

M.Th. Markus, PhD · T.H.G. Hoogendijk, MA Leiden University Medical Centre

Leiden, The Netherlands

F. Boer, $\mathrm{MD}, \mathrm{PhD}$

AMC Department of Child and Adolescent

Psychiatry/de Bascule

PO Box 12474

1100 AL Amsterdam, The Netherlands
Abstract Both temperament and parental child-rearing style are found to be associated with childhood anxiety disorders in population studies. This study investigates the contribution of not only temperament but also parental child-rearing to clinical childhood anxiety disorders. It also investigates whether the contribution of temperament is moderated by child-rearing style, as is suggested by some studies in the general population. Fifty children were included (25 with anxiety disorders and 25 non-clinical controls). Child-rearing and the child's temperament were assessed by means of parental questionnaire (Child Rearing Practices Report (CRPR) (Block in The Child-Rearing Practices Report. Institute of Human Development. University of California, Berkely, 1965; The Child-Rearing Practices Report (CRPR): a set of Q items for the description of parental socialisation attitudes and values. Unpublished manuscript. Institute of Human Development. University of California, Berkely, 1981), EAS Temperament Survey for Children (Boer and Westenberg in
J Pers Assess 62:537-551, 1994; Buss and Plomin in Temperament: early developing personality traits. Lawrence Erlbaum Associates, Inc, Hillsdale, 1984s). Analysis of variance showed that anxiety-disordered children scored significantly higher on the temperamental characteristics emotionality and shyness than non-clinical control children. Hierarchical logistic regression analyses showed that temperament (emotionality and shyness) and child-rearing style (more parental negative affect, and less encouraging independence of the child) both accounted for a unique proportion of the variance of anxiety disorders. Preliminary results suggest that child-rearing style did not moderate the association between children's temperament and childhood anxiety disorders. The limited sample size might have been underpowered to assess this interaction.

Key words temperament child anxiety disorder child-rearing style parent report 


\section{Introduction}

Paediatric anxiety is a serious condition affecting approximately $6-10 \%$ of young children and adolescents [65], which tends to show continuity through childhood and adolescence [25, 27, 66], and can follow a chronic pathway into adulthood $[20,36]$. The development of anxiety disorders in children is the result of a variety of factors. Especially temperament and parenting appear to be important aetiological factors $[8,10]$.

Temperament concerns the difference between individuals in their style of behaviour. Although temperament theorists differ with regard to issues such as the heritability of temperament, its relation to biological factors, and its stability through time and situations, there is a consensus that temperament consists of relatively consistent, basic dispositions inherent in the person that underlie and modulate the expression of activity, reactivity, emotionality and sociability [31]. Two temperamental traits stand out in the research of anxiety-disordered (AD) children: negative affectivity and shyness (or behavioural inhibition). Negative affectivity is generally defined as a temperamental sensitivity to negative stimuli, causing a broad range of negative moods, including fear/anxiety and sadness/ depression but also such emotions as guilt, hostility and self-dissatisfaction [11]. Children with this temperament easily get angry and can become very distressed, for instance when they are not allowed something they would like or after the occurrence of something unpleasant. Shyness, sometimes operationalized as 'behavioural inhibition' [23], is defined as the consistent tendency to display fear and withdrawal in unfamiliar situations, with or without a social component [22]. Children with this temperament are often reticent in social contacts. They are shy towards strangers and timid in unfamiliar situations. There is substantial evidence that children with stable high levels of behavioural inhibition [41] and/or high emotionality run a higher risk of developing anxiety disorders [38]. Whereas behavioural inhibition is considered a specific risk factor for anxiety [3], negative affectivity has been found to be associated with both internalising and externalising behaviour in later childhood [15]. The direction of these associations is still in need of clarification. Furthermore, some temperamental characteristics (e.g. high level of effortful control) shield the child from anxiety [38].

Parenting style is a multifaceted phenomenon, but the multitude of studies that have been performed since the 1950s show that many of its facets can be ordered in a circumplex pattern with two orthogonal dimensions: warmth versus hostility, and control versus autonomy [32]. Research has reliably demon- strated an association between parenting style and anxiety disorders in children. The parenting style of parents of $\mathrm{AD}$ children is characterised by over-control and increased criticism $[8,43]$. These associations may well be reciprocal, with child characteristics giving rise to certain child-rearing styles, which in turn may instigate and reinforce the child's characteristics [8].

The established contributions of temperament and parenting to anxiety disorders in children might be merely additive, but could also show interaction. Research in the general population has produced equivocal results.

Studies of adults looking back upon their youth show associations between rearing style and temperament: perceived limited care or an excess of control by the parents is connected with more harm avoidance or shyness $[14,46,47,53]$. It is likely that this association is the product of interaction. The child's temperament may impact on parenting behaviours, and parenting may moderate the expression of temperament as well [31]. A temperamentally based differential susceptibility [2] to child-rearing has been demonstrated in population studies. This suggests that parenting serves as a moderator between temperament and anxiety [31, 63]. In a sample of preadolescents the depressogenic effect of parental overprotection and lack of emotional warmth proved to be dependent on the child's temperament [40]. Also, children reared with less care or more control were shown to be more vulnerable to anxiety when they have a behaviourally inhibited temperament [12, 29, 52]. One study [37] showed differences in the behavioural problems of temperamentally highly irritable children dependent on the type of childrearing: maternal psychological control was associated with internalizing problems, whereas maternal hostility was associated with externalizing problems. Other population studies, however, failed to find such interactive effects. In a cross-sectional study of 644 children and adolescents inhibited temperament, as well as parental control and anxious rearing were found to be associated with higher levels of anxious symptoms, but no interactive effects were found [64].

Using data collected in an ongoing longitudinal study of vulnerability and resilience among boys of low-income families, Feng and colleagues [16] were able to clarify the differential contributions of temperament and parenting to childhood anxiety during the developmental trajectory. Temperament (shyness) appeared strongly related to anxiety levels in early childhood, but parenting (high control) proved to be more contributing for anxiety that emerges in middle childhood or preadolescence, even among children who were not initially anxious. 
In summary, parenting and temperament are both risk factors for anxiety in general populations [44]. It is an important research question whether this applies to clinical populations as well. This paper describes a controlled study of clinically referred AD children, which investigates whether AD children show higher levels of emotionality and shyness than normal controls. Secondly, it is hypothesised that childhood temperament and parental child-rearing style additively contribute to childhood anxiety disorders. Furthermore, on an exploratory level we investigated whether the contribution of temperament to anxiety disorders is moderated by child-rearing style.

\section{Method}

\section{Patient sample}

All families of children (aged 8-13 years) referred consecutively to an outpatient clinic for child and adolescent psychiatry with anxiety disorder as the primary diagnosis and growing up in complete families, were asked to participate in the present study. Families were excluded if the child met criteria for the following DSM-III- ${ }^{1}$ diagnoses: mental retardation, pervasive developmental disorder or schizophrenia. Of the 35 eligible families 25 participated after signing informed consent. Ten families refused to participate for various reasons (mostly time constraints, sometimes the concern that the research would burden the child). Families which agreed to participate and those which declined did not differ significantly in the average age of the child, gender distribution of children and average income. The clinical families included 11 girls and 14 boys ( $M=10.8$ years old) with anxiety disorders. The AD children had a diagnosis, as determined by means of the Anxiety Disorders Interview Schedule (ADIS-C/P) [54, 55, 59], of overanxious disorder $(N=15)$, generalised anxiety disorder $(N=2)$, separation anxiety disorder $(N=16)$, social phobia $(N=10)$ or panic disorder without agoraphobia $(N=2)$, according to DSM-III-R criteria [1]. Additional comorbid anxiety disorders were simple phobia $(N=8)$ and posttraumatic stress disorder $(N=1)$. Comorbidity among the anxiety disorders was common, with $56 \%$ of the children having more than one anxiety disorder diagnosis. Five AD children also had a diagnosis of dysthymia, two AD children had a major depression, and one AD child had a comorbid mood disorder of dysthymia and major depression.

\footnotetext{
${ }^{1}$ At the time of the study the DSM IV version of the ADIS-C was not yet available in its Dutch version.
}

\section{Control sample}

The non-clinical control group was recruited from circles of friends and acquaintances of the clinical families, to ensure optimal similarity in cultural and socio-economic status. The control group consisted of 25 two-parent families of which one child, within the age range of 7-13 years, participated. The children were 10 girls and 15 boys $(M=10.9$ years old $)$. The children in this group had never used mental health services. They were assessed by means of a semi-structured diagnostic interview [54, 55, 59] (ADIS-C/P). If this revealed evidence of psychopathology the children were not included in the study. In seven of the original 32 families which were approached the child appeared not to be free from psychopathology. These families were therefore excluded.

The patient and control samples did not significantly differ in gender, age, birth order of the child, family income and ethnicity (Caucasian).

\section{Measures}

\section{Psychiatric assessment}

The ADIS-C and ADIS-P [59] are semistructured interviews with the child and one of its parents, respectively. In this study a Dutch version of both interviews was used, which has been developed by Siebelink and Treffers [54, 55]. The ADIS-C assesses all DSM-III-R anxiety and mood disorders, whereas the ADIS-P assesses some additional mental disorders (e.g. externalising disorders, psychosis and substance abuse) to be ruled out. The interrater and test-retest reliability of the ADIS are satisfactory, both at the level of individual symptoms and at the level of classifications [56, 57, 60]. All ADIS-C and ADIS-P interviews were scored twice, with the two interviewers of this study scoring independently. The interrater reliability (based on the scoring of audiotaped ADIS-interviews) was good, with kappa $=0.89$ and 0.90 for the child and the parent interviews, respectively. In this study the ADIS-P regarding the AD child was administered to one parent (mother or father chosen randomly).

\section{Child-rearing style}

The CRPR [4, 5] assesses attitudes, values, goals and behaviours of parents with regard to child-rearing [5]. It is administered to children ranging in age from preschool [21] to late adolescence [17], and has shown stability through time $[35,49]$. Originally the CRPR consisted of 91 socialization statements in a Q-sort 
format. Deković and colleagues [13] developed a questionnaire format of the CRPR, with a 6-point Likert-type scale (ranging from $1=$ not at all descriptive of me, to $6=$ highly descriptive of me). The questionnaire format has proved to have good reliability as well as construct validity [13].

Factor analysis has shown two main factors: Nurturance and restrictiveness [13, 48]. Some subscales of the original CRPR version, of which the items do not overlap with the two main scales, are also relevant to the investigation of parental warmth versus rejection, and control versus autonomy, i.e. negative affect toward child (Cronbach's alpha $=0.61$ ), worry about the child (Cronbach's alpha $=0.59$ ), encouraging independence (Cronbach's alpha $=0.69$ ). That is why, for the purpose of our study, we used these subscales in addition to the main scales.

\section{Temperament}

The EAS Temperament Survey for Children (parental ratings) [9] is a parental rating questionnaire consisting of four scales, each represented by five items: (a) the emotionality scale, which measures distress, (b) the activity scale, which measures tempo and vigor, (c) the shyness scale, which measures inhibition and tension when with unfamiliar others, and (d) the experimental sociability scale, which measures the preference for being with others to being alone. The psychometric properties of the Dutch translation of the EAS have been excellent for the emotionality, activity, and shyness scales. The results regarding the experimental sociability scale are ambiguous [7]. Age and gender of the child do not influence the overall reliability and validity $[9,18,19,42,67]$. The EAS has been used in clinical and community samples $[26,33$, $45,62]$, in childhood as well as adolescence $[9,18,42$, 67].

\section{Procedure}

The study was approved by the institutional review board of Leiden University Medical Centre. Informed consent was obtained from all participating parents and children. The EAS was filled out by mothers. The CRPR was filled out by both parents separately. The ADIS-C/P was administered at home.

\section{Data analysis}

Differences in temperament between $25 \mathrm{AD}$ children and 25 control children were investigated by using analysis of variance. The findings were re-examined by conducting analysis of variance with gender, age
Table 1 EAS: anxiety-disordered children (AD) versus non-clinical control (NCC) children

\begin{tabular}{lllll}
\hline & $\begin{array}{l}\text { AD-children } \\
(n=25) \\
\text { Mean (SD) }\end{array}$ & $\begin{array}{l}\text { NCC-children } \\
(n=25) \\
\text { Mean (SD) }\end{array}$ & $F(48,1)$ & $P$ value \\
\hline Activity & $3.3(0.9)$ & $3.3(0.6)$ & 0.13 & $<0.001$ \\
Emotionality & $3.7(0.8)$ & $2.4(0.8)$ & 36.27 & $<0.001$ \\
Sociability & $3.3(0.7)$ & $3.6(0.7)$ & 1.32 & \\
Shyness & $2.8(0.9)$ & $1.9(0.6)$ & 16.72 & \\
\hline
\end{tabular}

and birth order of the child as covariates. All significant findings remained significant.

To examine whether temperament and child-rearing both contribute to childhood anxiety disorders, and, in addition, whether the effect of temperament was moderated by parenting style, logistic regression analyses were performed. For each EAS scale, associated with anxiety disorders, a separate hierarchical logistic regression analysis was employed, in which the temperament rating and (sub)scales of the CRPR were stepwise added to the model. For the logistic regression analyses, aggregated scores for parental style were used to reduce the potential number of predictor variables and number of analyses. Composite scores were based on means across mothers and fathers. This data reduction was justified since it was based on moderate intercorrelations among fathers and mothers (range $r s=0.20-0.40$ ).

\section{Results}

Table 1 presents temperamental differences between $\mathrm{AD}$ children and normal controls. The differences regarding emotionality and shyness are significant when $\mathrm{AD}$ children are compared with controls.

In order to test for collinearity, correlations were examined. For emotionality significant correlations were found with nurturance $(-0.26 ; P<0.05)$, negative affect $(0.55 ; \quad P<0.001)$ and worry $(0.43$; $P<0.01)$. Significant correlation for shyness were found with negative affect $(0.32 ; P<0.05)$ and worry (0.47; $P<0.001)$. As the correlations between these variables do not exceed 0.8 , the relationships between the independent variables will not pose problems in the logistic regression analyses.

To examine relations between $\mathrm{AD}$ on the one hand and temperament and parenting style on the other hand, we regressed $\mathrm{AD}$ on temperament, parenting style, and the interaction of temperament and parenting style. With 50 subjects the power to investigate the interaction between temperament and parenting is limited, and this means that these results should be interpreted with caution [24]. The logistic regression 
Table 2 Logistic regression of temperament-emotionality (EAS) and childrearing (CRPR) on anxiety disorders

\begin{tabular}{lccccc}
\hline & OR & Wald & $P$ value & $95 \% \mathrm{Cl}$ & Nk $R^{2}$ \\
\hline Emotionality (EAS) $^{\mathrm{a}}$ & 0.16 & 7.0 & 0.008 & $0.04-0.63$ & \\
Negative affect (CRPR) $^{\mathrm{b}}$ & 0.61 & 5.6 & 0.018 & $0.40-0.92$ & \\
$\begin{array}{c}\text { Encouraging independence } \\
\quad(\mathrm{CRPR})^{\mathrm{b}}\end{array}$ & 1.23 & 3.5 & 0.063 & $1.00-1.53$ & $0.74^{\mathrm{b}}$ \\
& & & & & \\
\hline
\end{tabular}

$O R$ unadjusted odds ratio, $C l$ confidence interval, $N k R^{2}$ Nagelkerke $R^{2}$

${ }^{\text {a }}$ Step $1 \mathrm{LRA} ; \chi^{2}(d f=1)=28.24, P<0.001$

${ }^{\mathrm{b}}$ Step $2 \mathrm{LRA} ; \chi^{2}(d f=3)=41.37, P<0.001 ; \chi_{\text {Improvement }}^{2}(d f=2)=13.13$, $P<0.001$

Table 3 Logistic regression of temperament-shyness (EAS) and childrearing (CRPR) on anxiety disorders

\begin{tabular}{llllll}
\hline & OR & Wald & $P$ value & $95 \% \mathrm{Cl}$ & Nk $R^{2}$ \\
\hline Shyness (EAS) $^{\mathrm{a}}$ & 0.28 & 5.1 & 0.024 & $0.09-0.85$ & \\
Negative affect (CRPR) $^{\mathrm{b}}$ & 0.54 & 8.8 & 0.003 & $0.34-0.81$ & \\
$\begin{array}{l}\text { Encouraging independence } \\
\quad(\mathrm{CRPR})^{\mathrm{b}}\end{array}$ & 1.22 & 3.9 & 0.050 & $1.00-1.50$ & $0.72^{\mathrm{b}}$ \\
\hline
\end{tabular}

$O R$ unadjusted odds ratio, $C l$ confidence interval, $N k R^{2}$ Nagelkerke $R^{2}$

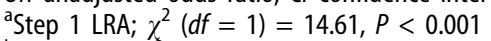

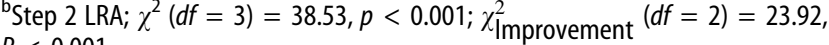
$P<0.001$

analyses were restricted to the temperament scales for which differences were found between the $\mathrm{AD}$ and control group, i.e. emotionality and shyness. In an initial analysis child gender and age had been entered in the first step, but these variables were subsequently removed because, as expected, they were not significantly related to the outcome variable.

Separate logistic regression analyses were undertaken for the two temperament scales shyness and emotionality with $\mathrm{AD}$ as outcome. In these analyses variables were entered in the following order: temperament in the first step, the parenting scales in the second step as a block, and lastly, the temperament $\times$ parental style interaction terms as a block. At the second step variables were selected by means of backward elimination of the parenting variables.

Results (Table 2) indicated significant associations between the temperament emotionality rating and the presence of an anxiety disorder in the child. The likelihood of an anxiety disorder in the child is higher when the child's temperament rating of emotionality is higher. When we included the parenting variables in the second step of the logistic regression analysis, the parenting variables negative affect and encouraging independence of the child (trend: $P=0.063$ ) accounted for a significant $17 \%$ of the variance in $\mathrm{AD}$ in addition to emotionality. The model predicts that, as parents' negative affect increases and the independence of the child is less encouraged, the likelihood of the presence of anxiety disorders in the child will increase. Overall, the variables together accounted for $74 \%$ of the variation in $\mathrm{AD}$. Interactions between emotionality and parenting measures did not approach significance.

In a second logistic regression analysis (Table 3 ) the temperament shyness rating was significant in predicting the presence of an anxiety disorder in the child. Again, the parenting variables negative affect and encouraging independence of the child contributed significantly to the model beyond the effect of the temperament shyness rating. Parents with higher levels of negative affect and lower levels of encouraging independence were significantly more likely to have a child with an anxiety disorder. This logistic regression model was statistically significant, with the variable scores together accounting for $72 \%$ of the variation in anxiety disorders. This was substantially more than that explained by the temperament rating of shyness alone, i.e. 34\%. Interactions between shyness and parenting measures did not approach significance.

\section{Discussion}

This study is, to the best of our knowledge, the first to extend the findings from general population studies by examining the contribution of temperament and child-rearing to clinical childhood anxiety disorders, as well as the potentially moderating role of parenting style. It was able to replicate earlier studies of mainly population samples in demonstrating temperamental differences between children in middle childhood with anxiety disorders and those without. In this study the EAS temperaments emotionality and shyness proved to be higher in $\mathrm{AD}$ children than in normal controls. Previously, we found that childrearing style with regard to $\mathrm{AD}$ children compared to that towards normal control children and siblings was characterised by more rejection/criticism and more control [30]. In the present study we found that temperament (emotionality and shyness) and parenting style (over-controlling and rejective) have an additive effect. Furthermore, logistic regression analyses showed that the effect of temperament in childhood anxiety disorders was not moderated by parental child-rearing style. Thus, this study does not support a differential temperamental susceptibility for the impact of anxiety inducing child-rearing practices.

The additive effect of temperament of the child and parental child-rearing style without an additional moderating effect of child-rearing on temperament suggests that both factors represent separate paths in the development of anxiety, without parental rearing style moderating the effect of temperament on anxiety disorders. Shyness, for instance, can contribute to social anxiety in peer relationships [39]. Furthermore, parenting style in middle childhood can impact rela- 
tions to the outside world because parental negative affect can cause the child to feel left to its own devices without feeling able to cope [8].

The present study shows limitations that need to be addressed. The small sample size limited the power of the analyses. Limited power and the relatively large amount of explained variance in the first steps of the logistic regression analyses may have caused the lack of significant interaction terms. Separate and combined analyses of larger samples of normal controls and $\mathrm{AD}$ children and the inclusion of a continuous measure of anxiety will allow a better investigation of interaction patterns. The absence of a clinical control group precludes judgement of the specificity of these results for $A D$ children rather than for children with mental disorders in general. Other studies have shown that the associations between the temperaments emotionality and shyness and anxiety disorders are independent of co-morbid depression [33]. Our results seem to imply that child-rearing style is not in response to the temperamental characteristics of children which were examined in this study. However, due to the cross-sectional nature of this study, we cannot rule out the possibility that the disorder influenced the parental judgment of the child's temperament. Furthermore, it remains to be seen whether studies with other informants of child-rearing and temperament (such as the children, or observers) will confirm the present findings or show different results. There is also the concern of an overlap between characteristics of anxiety disorders and characteristics of certain temperaments. However, there is evidence that elimination of confounding items in the measurements does not bring down the magnitude of the associations between these concepts [28].

We have to acknowledge the possibility that different temperamental constructs from the ones included in this study, especially effortful control [51], would have yielded other results. It is hypothesised that it takes the combination of high emotionality and low effortful control to make children more prone to developing psychological disorders [31]. In addition, we have to take into consideration that in the development of anxiety disorders child-rearing may interact with personality factors [34], which were not included in the present study, for example ego-resilience [61].
Despite these limitations the results of the present study have important consequences. The association between temperamental characteristics and anxiety disorders has raised the question whether these characteristics will be useful markers for selecting children for primary prevention or early intervention protocols $[6,50]$. The additive contribution of parenting style adds an interesting component to the way primary prevention could be conducted. It suggests that, in addition to identification of temperamentally vulnerable children, it is important to identify parents inclined to be critical or to discourage their child's independence. It is helpful for clinicians to keep in mind that these parental behaviours often are maladaptive ways of coping with the anxiety of the child, and to know that providing education to parents can be very successful [58].

\section{Summary}

Temperament and parental child-rearing are suggested to be important aetiological factors in developing childhood anxiety disorders. The present study investigated whether temperamental characteristics of the child as well as child-rearing style-both assessed by means of parent-report-contribute independently to the prediction of clinical anxiety disorders in primary-school-age children. To extend findings from general population studies, we also investigated whether the contribution of temperament is moderated by child-rearing style. Temperamental emotionality and shyness as well as more parental negative affect and less encouragement of the child's independence each account for a unique proportion of the variance of childhood anxiety disorders. These findings support an additive model. No support has been found for a moderating role of child-rearing style between the child's temperament and childhood anxiety disorders, although a moderating role might have been obscured due to the limited sample size.

Acknowledgments Thanks are due to the participating families and staff members of Curium. We gratefully acknowledge the support of Sophie R. Borst, Marjo Borsje and Ragna Maignay, in conducting this study and Hein Putter for his statistical advises. Completion of this study was facilitated by Grant 4105 from the Dutch National Fund for Mental Health.

\section{References}

1. American Psychiatric Association (1987) Diagnostic and statistical manual of mental disorders, third editionrevised DSM-III-R. American Psychiatric Association, Washington, DC
2. Belsky J (1997) Theory testing, effectsize evaluation, and differential susceptibility to rearing influence: the case of mothering and attachment. Child Dev 64(4):598-600
3. Biederman J, Hirshfeld-Becker DR, Rosenbaum JF, Hérot C, Friedman D, Snidman N, Kagan J, Faraone SV (2001) Further evidence of association between behavioral inhibition and social anxiety in children. Am J Psychiatry 158:1673-1679 
4. Block JH (1965) The Child-Rearing Practices Report. Institute of Human Development. University of California, Berkely

5. Block JH (1981) The Child-Rearing Practices Report (CRPR): a set of Q items for the description of parental socialisation attitudes and values. Unpublished manuscript. Institute of Human Development. University of California, Berkely

6. Boer F, Stegge H, Akyuz H (2007) Recognition of children of preschool age at risk for internalising disorders in mainstream and Islamic primary care. Int J Ment Health Promotion 9:17-24

7. Boer F, Westenberg PM (1994) The factor structure of the Buss and Plomin EAS Temperament Survey (parental ratings) in a Dutch sample of elementary school children. J Pers Assess 62:537-551

8. Bögels SM, Brechman-Toussaint L (2006) Family issues in child anxiety: attachment, family functioning, parental rearing and beliefs. Clin Psychol Rev 26:834-856

9. Buss AH, Plomin R (1984) Temperament: early developing personality traits. Lawrence Erlbaum Associates, Inc, Hillsdale

10. Chorpita BF, Barlow DH (1998) The development of anxiety: the role of control in the early environment. Psychol Bull 124:3-21

11. Clark LA, Watson D, Mineka S (1994) Temperament, personality, and the mood and anxiety disorders. J Abnorm Psychol 103:103-116

12. Crockenberg SC, Leerkes EM (2006) Infant and maternal behavior moderate reactivity to novelty to predict anxious behavior at 2.5 years. Dev Psychopathol 18:17-34

13. Deković M, Janssens JMAM, Gerris JM (1991) Factor structure and construct validity of the Block Child Rearing Practices Report (CRPR). Psychol Assess J Consult Clin Psychol 3:182-187

14. Eastburg M, Johnson WB (1990) Shyness and perceptions of parental behavior. Psychol Rep 66:915-921

15. Eisenberg N, Sadovsky A, Spinrad TL, Fabes RA, Losoya SH, Valiente C, Reiser M, Cumberland A, Shepard SA (2005) The relations of problem behavior status to children's negative emotionality, effortful control, and impulsivity: concurrent relations and prediction of change. Dev Psychol 41:193-211

16. Feng X, Shaw DS, Silk JS (2008) Developmental trajectories of anxiety symptoms of boys across early and middle childhood. J Abnorm Psychol 117:32-47
17. Gerhardt CA, Vannatta K, McKellop JM, Tayler J, Passo M, Reiter-Purtill J, Zeller M, Noll RB (2003) Brief report: child-rearing practices of caregivers with and without a child with juvenile rheumatoid arthritis: perspectives of caregivers and professionals. J Pediatr Psychol 28:275-279

18. Gibbs MV, Reeves D, Cunningham CC (1987) The application of temperament questionnaires in a British sample: issues of reliability and validity. J Child Psychol Psychiatry 28:61-67

19. Goodyer IM, Ashby L, Altham PME, Vize C, Cooper PJ (1993) Temperament and major depression in 11-16 year olds. J Child Psychol Psychiatry 34:1409-1423

20. Hadwin JA, Garner M, Perez-Olivas G (2006) The development of information processing biases in childhood anxiety: a review and exploration of its origins in parenting. Clin Psychol Rev 26:879894

21. Hastings PD, Rubin KH (1999) Predicting mothers' beliefs about preschool-aged children's social behavior: evidence for maternal attitudes moderating child effects. Child Dev 70:722741

22. Kagan J, Reznick JS, Clarke C, Snidman N, Garcia-Coll C (1984) Behavioral inhibition to the unfamiliar. Child Dev 55:2212-2225

23. Kagan J, Reznick JS, Snidman N (1987) The physiology and psychology of behavioral inhibition in children. Child Dev 58:1459-1473

24. Katz MH (2006) Setting up a multivariable analysis. In: Katz MH (ed) Multivariable analysis: a practical guide for clinicians. Cambridge University Press, New York

25. Keller MB, Lavori PhW, Wunder J, Beardslee WR, Schwartz CE, Roth J (1992) Chronic course of anxiety disorders in children and adolescents. J Am Acad Child Adolesc Psychiatry 31:595-599

26. Kelvin RG, Goodyer IM, Altham PME (1995) Temperament and psychopathology amongst siblings of probands with depressive and anxiety disorders. J Child Psychol Psychiatry 37:543-550

27. Kovacs M, Devlin B (1998) Internalizing disorders in childhood. J Child Psychol Psychiatry 39:47-63

28. Lemery KS, Essex MJ, Smider NA (2002) Revealing the relation between temperament and behavior problem symptoms by eliminating measurement confounding: expert ratings and factor analyses. Child Dev 73:867-882
29. Leve LD, Kim HK, Pears KC (2005) Childhood temperament and family environment as predictors of internalizing and externalizing trajectories from ages 5 to 17. J Abnorm Child Psychol 33:505-520

30. Lindhout IE, Markus MT, Borst SR, Hoogendijk ThHG, Dingemans PMAJ, Boer F (in press) Childrearing style in families of anxiety-disordered children: between- and within-family differences. Child Psychiatry Hum Dev

31. Lonigan CJ, Phillips BM (2001) Temperamental influences on the development of anxiety disorders. In: Vasey MW, Dadds MR (eds) The developmental psychopathology of anxiety. Oxford University Press, New York, pp 60-91

32. Maccoby EE, Martin JA (1983) Socialization in the context of the family: parent-child interaction. In: Hetherington EM (ed) Handbook of child psychology. Wiley, New York, pp 1-101

33. Masi G, Mucci M, Favilla L, Brovedani P, Millepiedi S, Perugi G (2003) Temperament in adolescents with anxiety and depressive disorders and in their families. Child Psychiatry Hum Dev 33:245-259

34. McLeod BD, Wood JJ, Weisz JR (2006) Examining the association between parenting and childhood anxiety: a meta-analysis. Clin Psychol Rev 27:155-172

35. McNally S, Eisenberg N, Harris JD (1991) Consistency and change in maternal child-rearing practices and values: a longitudinal study. Child Dev 62:190-198

36. Merikangas KR, Zhang H, Avenevoli S, Acharyya S, Neuenschwander M, Angst J (2003) Longitudinal trajectories of depression and anxiety in a prospective community study. The Zurich Cohort Study. Arch Gen Psychiatry 60:9931000

37. Morris AS, Silk JS, Steinberg L, Sessa FM, Avenevoli S, Essex MJ (2002) Temperamental vulnerability and negative parenting as interacting predictors of child adjustment. J Marriage Fam 64:461-471

38. Muris P, Th Ollendick (2005) The role of temperament in the etiology of child psychopathology. Clin Child Fam Psychol Rev 8:271-289

39. Neal JA, Edelmann RJ (2003) The etiology of social phobia: toward a developmental profile. Clin Psychol Rev 23:761-786

40. Oldehinkel AJ, Veenstra R, Ormel J, de Winter AF, Verhulst FC (2006) Temperament, parenting, and depressive symptoms in a population sample of preadolescents. J Child Psychol Psychiatry 47:684-695 
41. Perez-Edgar K, Fox NA (2005) Temperament and anxiety disorders. Child Adolesc Psychiatric Clin N Am 14:681706

42. Plomin R, Dunn J (1986) The study of temperament: changes, continuities and challenges. Erlbaum, Hillsdale

43. Rapee RM (1997) Potential role of childrearing practices in the development of anxiety and depression. Clin Psychol Rev 17:47-67

44. Rapee RM (2002) The development and modification of temperamental risk for anxiety disorders: prevention of a lifetime of anxiety? Biol Psychiatry 52:947957

45. Rende RD (1993) Longitudinal relations between temperament traits and behavioral syndromes in middle childhood. J Am Acad Child Adolesc Psychiatry 32:287-290

46. Reti IM, Samuels JF, Eaton WW, Bienvenu OJIII, Costa PT Jr, Nestadt G (2002) Influences of parenting on normal personality traits. Psychiatry Res 111:55-64

47. Richter J, Eisemann M, Richter G (2000) Temperament, character and perceived parental rearing in healthy adults: two related concepts? Psychopathology 33:36-42

48. Rickel AV, Biasatti LL (1982) Modifications of the Block Child Rearing Practices Report. J Clin Psychol 38:129134

49. Roberts GC, Block JH, Block J (1984) Continuity and change in parents' child-rearing practices. Child Dev 55:586-597

50. Rosenbaum JF, Biederman J, HirshfeldBecker DR, Kagan J, Snidman N, Friedman D, Nineberg A, Gallery DJ, Faraone SV (2000) A controlled study of behavioral inhibition in children of parents with panic disorder and depression. Am J Psychiatry 157:20022010
51. Rothbart MK, Bates JE (1998) Temperament. In: Eisenberg N, Damon W (eds) Handbook of child psychology: social, emotional, and personality development, vol 3. Wiley, New York, pp 105-176

52. Rubin KH, Burgess KB, Hastings PD (2002) Stability and social-behavioral consequences of toddlers' inhibited temperament and parenting behaviors. Child Dev 73:483-495

53. Schlette P, Brändström S, Eisemann $M$, Sigvardsson S, Nylander P, Adolfsson R, Perris C (1998) Perceived parental rearing behaviours and temperament and character in healthy adults. Personality Individ Differ 24:661-668

54. Siebelink BM, PhDA Treffers (1995) Anxiety Disorders Interview Schedule for DSM-III-R, Child version. Academic Centre for Child and Adolescent Psychiatry Curium, Oegstgeest

55. Siebelink BM, PhDA Treffers (1995) Anxiety Disorders Interview Schedule for DSM-III-R, Parent version. Academic Centre for Child and Adolescent Psychiatry Curium, Oegstgeest

56. Silverman WK (1991) Diagnostic reliability of anxiety disorders in children using structured interviews. J Anxiety Disord 5:105-124

57. Silverman WK, Eisen AR (1992) Age differences in the reliability of parent and child reports of child anxious symptomatology using a structured interview. J Am Acad Child Adolesc Psychiatry 31:117-124

58. Silverman WK, Kurtines WM, Ginsburg GS, Weems CF, Rabian B, Serafini LT (1999) Contingency management, self-control, and education support in the treatment of childhood phobic disorders: a randomized clinical trial. J Consult Clin Psychol 67:675-687

59. Silverman WK, Nelles WB (1988) The anxiety disorders interview schedule for children. J Am Acad Child Adolesc Psychiatry 27:772-778
60. Silverman WK, Rabian B (1995) Testretest reliability of the DSM-III-R childhood anxiety disorders symptoms using the anxiety disorders interview schedule for children. J Anxiety Disord 9:139-150

61. Smeekens S, Riksen-Walraven JM, van Bakel HJA (2007) Cortisol reactions in five-year-olds to parent-child interaction: the moderating role ego-resiliency. J Child Psychol Psychiatry 48:649-656

62. Smith J, Prior M (1995) Temperament and stress resilience in school-age children: a within-families study. J Am Acad Child Adolesc Psychiatry 34:168179

63. Turner SM, Beidel DC, Wolff PL (1996) Is behavioral inhibition related to the anxiety disorders? Clin Psychol Rev 16:157-172

64. Van Brakel AML, Muris P, Bögels SM, Thomassen C (2006) A multifactorial model for the etiology of anxiety in non-clinical adolescents: main and interactive effects of behavioural inhibition, attachment and parental rearing. J Child Fam Stud 15:569-579

65. Verhulst FC (2001) Community and epidemiological aspects of anxiety disorders in children. In: Silverman WK, PhDA Treffers (eds) Anxiety disorders in children and adolescents. Research assessment and intervention. Cambrigde University Press, Cambridge, pp 273-292

66. Verhulst FC, van der Ende J (1995) The eight-year stability of problem behavior in an epidemiologic sample. Pediatr Res 38:612-617

67. Wamboldt M, Chipuer S (1990) The reliability and validity of the EAS scales. Unpublished manuscript. Center for Development and Human Genetics, College of Health and Human Development. The Pennsylvania State University 